\title{
Patient education, nudge, and manipulation: defining the ethical conditions of the person- centered model of care
}

This article was published in the following Dove Press journal:

Patient Preference and Adherence

4 April 2016

Number of times this article has been viewed

\author{
Gérard Reach ${ }^{1,2}$ \\ 'Department of Endocrinology, \\ Diabetes and Metabolic Diseases, \\ Avicenne Hospital AP-HP, ${ }^{2}$ EA 3412 , \\ Centre de Recherche en Nutrition \\ Humaine lle-de-France (CRNH-IDF), \\ Paris 13 University, Sorbonne Paris \\ Cité, Bobigny, France
}

\begin{abstract}
Patient education (PE) is expected to help patients with a chronic disease to manage their lives and give them the possibility of adopting, in an appropriate manner, beneficial changes in health behaviors that are prescribed by their physicians. It is aimed at delineating, agreeing on, and implementing a patient's personal action plan and is therefore an essential constituent of the person-centered model of care. The aim of this article is to examine the idea that PE may sometimes be a manipulation that is organized for the good of patients in a paternalistic framework. Theoretically, PE differs from manipulation by addressing the reflective intelligence of patients in full light and helping them make autonomous choices. In this article, we examined some analogies between PE and nudge (ie, techniques used to push people to make good choices by organizing their environment). This analysis suggests that PE is not always as transparent and reflective as it is supposed to be and that unmasking these issues may be useful for improving the ethical quality of educational practice that must be performed in a framework of a trusting patient-doctor relationship. Under this condition, PE may sometimes represent a form of persuasion without being accused of patient deception and manipulation: trust is therefore the core of the person-centered model of care.
\end{abstract}

Keywords: patient education, adherence, autonomy, nudge, persuasion, manipulation, deception, trust, person-centered care model, shared decision-making

\section{Introduction}

Patient nonadherence is an obvious obstacle to the quality and safety of care in daily medicine. It reduces the effectiveness of treatments, represents an important cause of hospitalization and mortality, and leads to considerable health expenditures that could otherwise be avoided. The World Health Organization (WHO) claimed that "increasing the effectiveness of interventions on adherence would have a greater impact on the health of the population than any improvement in medical treatments." This suggests that the health authorities recommend improving patients' adherence as a desirable objective.

According to the WHO, patient education (PE) is an integral part of treatment. It aims to ensure that patients with a chronic disease learn to manage their life and work together with the health care team in the implementation of treatment. ${ }^{2}$ In terms of therapy, PE provides patients with information, which makes the therapy more efficient and safe. PE may also indirectly improve patients' adherence, for their best interests, by providing them with an opportunity to better understand the benefits of changes in health behaviors that are recommended by health authorities and prescribed by their physicians. However, it is not because a procedure is aimed at improving
Correspondence: Gérard Reach Department of Endocrinology, Diabetes and Metabolic Diseases, Avicenne Hospital AP-HP, 125 Rue de Stalingrad, Bobigny 93000 , France

Tel +33 | 48955158

Fax +33 । 48955560

Email gerard.reach@aphp.fr (c) (1) (5) 2016 Reach. This work is published and licensed by Dove Medical Press Limited. The full terms of this license are available at https://www.dovepress.com/terms.php cc) hereby accept the Terms. Non-commercial uses of the work are permitted without any further permission from Dove Medical Press Limited, provided the work is properly attributed. For permission for commercial use of this work, please see paragraphs 4.2 and 5 of our Terms (https://www.dovepress.com/terms.php). 
the patients' welfare that PE is ethically warranted. In other words, in a Kantian perspective, the end never justifies the means. Therefore, it is important to ensure that the laudable wish of improving the patients' adherence does not use PE as a disguised manipulation organized in a paternalistic framework.

The argument presented herein refers to recent ethical discussions on the concept of nudge, which was popularized by the best seller titled Nudge: Improving Decisions about Health, Wealth and Happiness, written by Thaler and Sunstein, that describes the techniques developed within the framework of public policy to push people to make good choices by organizing their environment. ${ }^{3}$ This analysis by analogy may unmask some potentially questionable aspects of PE, thereby deserving due consideration.

\section{The concept of nudge, its mechanisms of action, and ethics}

Thaler and Sunstein described nudge as a set of techniques intended to encourage people to change their behavior by using gentleness rather than coercion and the threat of sanctions. Nudge acts by changing the architecture of choice; for example, in a cafeteria, putting fruits and yogurts in the front and junk foods in the back of the food tray. People remain free to choose, but they are nudged toward the right decisions that lead them to do what people within the health care system want them to do. Another well-known example can be found in the toilets of Amsterdam airport, where a false fly is engraved on the bottom of the urinal. This encourages men to aim at the fly, which led to an $80 \%$ reduction in cleaning costs. Here again, nudged individuals are free to decide whether or not to aim at the fly; however, numerous individuals do it, which limits cleaning costs and therefore has beneficial consequences for the society.

In their description of nudge, Thaler and Sunstein proposed that it acts at system 1 of thinking, which is fast (using heuristics), effortless, uncontrolled, unconscious, and skilled, rather than at system 2, which is slow, effort demanding, controlled, reflective, and consisting of deliberation. ${ }^{4}$ By acting at system 1 , nudge does not prohibit the individual from using his or her system 2; it only exploits flaws that are often present in the mechanisms of human decisions. Hansen and Jespersen ${ }^{5}$ recently proposed that there are two types of nudges. First, type 1 nudges work by influencing individuals' behaviors without engaging their reflective thinking. They provide as an example the decrease in the size of plates in a cafeteria that will help reduce the customers' caloric intake as they will place less food on their plates. Second, in type 2 nudges, the nudge-activated thinking in system 1 triggers the activation of system 2 . The fly in the urinal is a typical example of the type 2 nudge:

This nudge aims at capturing the visual search processes continuously performed by automatic thinking. When this happens, the nudge works by attracting reflective attention. ${ }^{5}$

Nudge has been referred to by Thaler and Sunstein as libertarian paternalism as this method organizes choices without force. In principle, the nudgees remain free not to perform the action to which they are being compelled. While in medicine, paternalism has a pejorative connotation, this may not be the case in the realm of public policies. As pointed out by Cohen, 6 "the meaning of paternalism is quite dissimilar in public policy or legislation and interpersonal relations." Public policy or legislation may refer more toward utilitarian or common good approaches to ethics, while interpersonal relations, characterizing the patient-physician relationship, refer for most ethicists to a Kantian perspective such as that used in the present discussion.

Therefore, due to its growing political importance, there has recently been an important debate on the ethical justification of nudge. If nudge organizes the environment to drive individuals to perform action A while leaving them free to exercise their deliberative capacity (to not perform action A if they do not wish so), it is clear that a crucial condition for the ethical acceptability of nudge is to maintain the capacity of the deliberation of individuals. According to Saghai, ${ }^{7}$ agents must remain able to easily resist the influence of nudge: thus, they:

[...] must i) be able to recognize the very existence of this influence, ii) be able to inhibit their triggered propensity to perform action A, and iii) not be in a state where these capabilities are disabled.

Under these conditions and free from undue influences, the freedom of choice of the nudgee remains intact and nudge may then be ethically acceptable.

\section{Manipulation and nudge: the red line}

These conditions of the ethical acceptability of nudge are not met in what is commonly called manipulation. According to Hansen and Jespersen, ${ }^{5}$ people are manipulated when their perceptions, choices, or behaviors are affected through underhanded deception or abusive tactics. Rubinelli ${ }^{8}$ also showed that, in manipulation, there is an intentional deception that remains covert, and this explains the difference between manipulation and persuasion. This distinction between persuasion and 
manipulation was also demonstrated by Dubov; ${ }^{9}$ persuasion is a form of influence where one person intends to produce a change in the behavior or opinions of another by using words to convey information, feelings or reasoning, or a combination thereof, while leaving enough freedom to choose otherwise. However, a victim of manipulation may falsely believe that he or she is acting in accordance to his or her will:

Manipulative strategies are designed to create an illusion of free choice to lure the victim into a decision that would be probably resisted under normal circumstances. ${ }^{9}$

This difference is important, and it provides an ethical justification of patients' persuasion in the patient-physician relationship ${ }^{10}$ even if it seems to be contrasting with the principle $^{11}$ of respecting the patient's autonomy. Joule and Beauvois $^{12}$ also defined manipulation as making people do things that they would not be inclined to do and that they will do thinking that they have made the decision by themselves. Several manipulative techniques can be used such as the foot-in-the-door ${ }^{13}$ technique and the commitment effect according to which people, once committed to a decision, become resistant to changing their minds. ${ }^{14}$ By discussing the mechanisms of action of these methods, Joule and Beauvois observed that their efficacy would disappear if they were unmasked. ${ }^{15}$

This may apply to nudge as well; for Bovens, nudge does work best in the dark. ${ }^{16}$ As shown earlier, ${ }^{7}$ a condition of the ethical acceptability of nudge is the possible cognitive access by the nudgee to the attempt to nudge. Therefore, one understands the emphasis on transparency as an ethical criterion for any method aimed at influencing behaviors. For example, it is important that television advertisements are displayed in well-delimited and announced spaces. Thus, Hansen and Jespersen ${ }^{5}$ distinguished two types of nudges: transparent nudges, where:

The nudgee can reasonably be expected to be able to easily reconstruct the intention behind the nudge and the means by which behavior change is pursued.

And nontransparent nudges, where this is not the case and where the covert intention to deceive is the mark of manipulation. For example, the fly in the urinal is a transparent nudge, while the shrinking of plate sizes aimed at reducing caloric intake is a nontransparent one. On the basis of these considerations, Hansen and Jespersen ${ }^{5}$ classified nudges into four classes: transparent type 2, transparent type 1, nontransparent type 2, and nontransparent type 1 . Their analysis suggested that nontransparent type 1 nudges are particularly questionable as they liken the most to manipulation. Considering the example of the employer who decreases the plate size in the cafeteria, they proposed it is important that:

The choice architect, ie, the employer, actively provides information to employees stating the reasons for and measures by which such steps are taken in order to avoid the accusation of manipulation, providing the possibility for a debate among employees. ${ }^{5}$

We used a similar approach to analyze the methods used in PE. If we consider that PE is also intended to lead patients to change their behavior, ${ }^{17}$ in other words to do (for their well-being) things that they would not be spontaneously inclined to do, we immediately see an analogy between $\mathrm{PE}$, on the one hand, and nudge and manipulation, on the other hand. An analysis of PE that is aimed at delineating the criteria making it, as for nudges, distinct from manipulation is therefore warranted. Again, it is not the endpoint of PE that matters. PE aims at improving the patient's welfare in the same manner that nudges are generally performed for their good. Incidentally, this could also be the case for some instances of manipulation; for example, the foot-in-the-door technique, ie, an overt manipulation has been used to make people accomplish beneficial health objectives such as recruiting teens to enroll in a smoking cessation program, convincing women to accept a gynecologic exam, making people call a taxi after drinking in a bar, or accepting the principle of organ donation. ${ }^{18}$ Therefore, this article analyzes from an ethical perspective not the endpoint but the methods used in PE.

\section{Principles of PE in a nutshell: involving cognitive and noncognitive aspects of health behaviors}

PE works through a learning process that consists of transforming new knowledge, insights, skills, and values into new behaviors. ${ }^{19}$ The $5 \mathrm{As}$ model is useful to describe the basis of the teaching process used to facilitate learning. ${ }^{20}$ It starts with an Assessment of patient knowledge, beliefs, current behaviors, and needs. The educator then Advises the patient by providing specific information about the health risks and benefits of changes. The patient and educator then Agree to define a list of specific goals, delineating the barriers and developing strategies to address them. The educator Assists the patient to identify personal barriers, strategies, problemsolving techniques, and social and environmental support. Finally, a follow-up plan is Arranged (eg, visits, phone calls, and mailed reminders). 


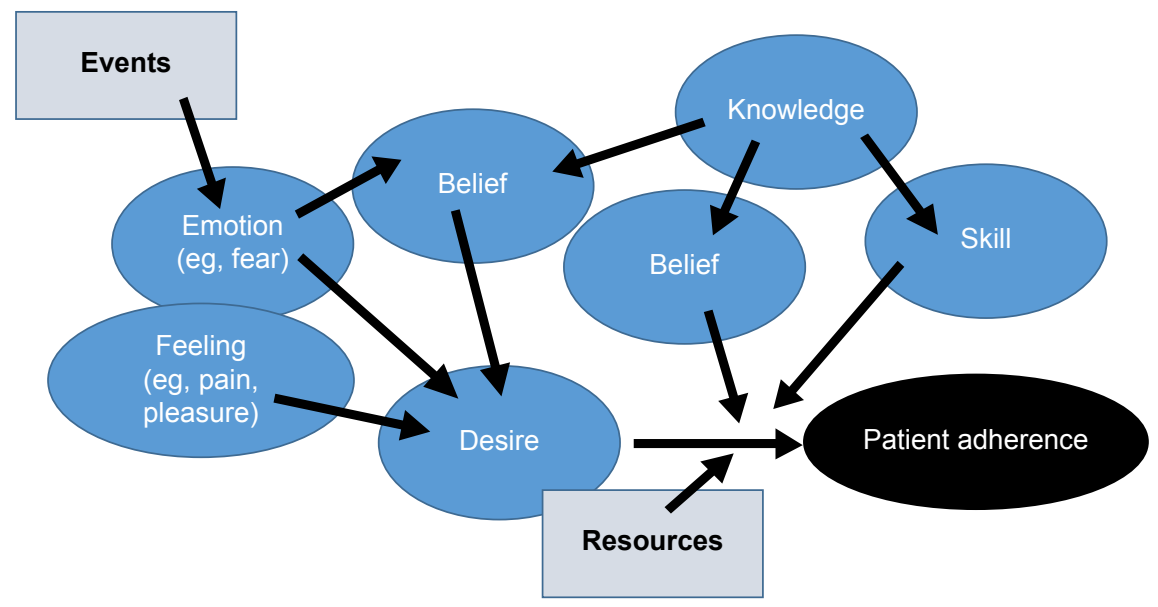

Figure I The mental mechanisms of patient adherence to long-term therapies: sites of action of patient education.

Notes: This figure represents the different mental states leading to patient adherence. They are the targets of patient education. PE: I) explores the content of the patient's different mental states (knowledge, skills, beliefs, emotions, and desires) as well as feelings such as pain and pleasure; 2) looks for events that could lead through emotions to a revision of beliefs and desires; and 3) investigates the patient's resources. By clarifying the barriers to adherence, patient education can indirectly improve it. Reproduced from The Mental Mechanisms of Patient Adherence to Long-Term Therapies, Mind and Care, Foreword by Pascal Engel, Philosophy and Medicine Series, An intentionalist model of patient adherence, 2015, Reach G. ${ }^{22}$ With permission of Springer.

Abbreviation: PE, patient education.

Therefore, PE is aimed at delineating, agreeing on, and implementing a patient's personal action plan. Philosophically, our actions are caused by reasons, ${ }^{21}$ which comprise mental states such as knowledge, skills, beliefs, emotions (generally triggered by the occurrence of events), and feelings such as pleasure and pain, and particularly desires, that are the real drivers of our actions; moreover, it is essential that we have the necessary resources. This explanatory model of action (Figure 1) that we have developed reflecting on why we take care of ourselves ${ }^{22}$ easily helps explain some causes of nonadherence: the patient does not know what to do, how to do it, is afraid to do it, cannot afford to do it, or does not want to do it. PE works by tackling these different causes of the patients' inaction.

However, these mechanisms of actions imply that the behavior consisting of treating oneself (or not) according to the doctor's prescriptions (the so-called adherence or nonadherence to treatment) is driven by both cognitive factors, such as knowledge, skills, and beliefs, and noncognitive factors such as emotions, pleasure, or pain and desire. This states the possibility that $\mathrm{PE}$ - aimed at changing patients' behaviors - is sometimes performed under a context lacking the transparency and reflectivity conditions that seem, at first glimpse from our analysis of nudge mechanisms and ethics, necessary to warrant its full ethical justification.

\section{Ethical justification of PE}

\section{The transparency requirement}

When patients have an appointment with a patient educator, it is likely that they will be ipso facto aware of the fact that they are entering into a PE process. Therefore, PE seems to implicitly represent a transparent procedure. However, this may not be always true for the following reasons: 1) PE is a continuous process involving numerous people, including physicians, nurses, and pharmacists who may want to educate patients without always clearly stating that they aim to influence their behaviors. 2) Even if the content of an educational session is clearly and explicitly defined in advance, the educator may influence the patient's behavior on an item of therapy that was not initially on the agenda, as the content of the information process cannot be completely described in advance. 3) The influential capacity of the conversation may remain elusive. Educators may say something during the conversation without explicitly realizing that they are actually providing information that will deeply influence the patient's behavior. This is due to the fact that, as proposed by American philosopher John Searle, ${ }^{23}$ the human mind should be considered a complex network made up of an infinite number of mental states (knowledge, beliefs, emotions, and desires) that he refers to as holism. These mental states differ among people: minds are different, not by their ways of thinking but by the content of what Searle calls intentional mental states, where the word intentional denotes the fact that they have content (for instance, if I believe that it rains, it rains is the content of my belief). 4) Finally, people have direct access, through what is referred to as the first-person authority, ${ }^{24}$ to the content of their own mental states but not to the minds of others, and this opacity of interpersonal relationships explains that deception, ie, manipulation, is possible.

The transparency condition may even be missing for another reason. The very process of PE, as described in the 
5As model, seems to imply transparency as the patient's personal action plan is decided by agreement (one of the As) between the patient and educator. This agreement can be observed as the endpoint of a discussion between the patient and educator on their respective preferences, ie, on their values ${ }^{25}$ in the framework of the deliberative model of patient-physician relationships described by Emanuel and Emanuel. ${ }^{26}$ We have previously proposed ${ }^{27}$ that PE can be defined as a process that paves an ethical pathway from the informative model (the educator provides the patient with information on his or her disease and treatment) to the interpretative model (the educator assists the patient in clarifying his or her preferences), arriving at the deliberative model (where they exchange views on their respective preferences). In this ethical definition of PE (Figure 2), PE would definitely distinguish from an advice provided in a pure paternalistic framework, where neither information nor exchange possibility is provided to the patient. If the rationale of the decision is hidden, paternalism can use manipulation even for the good of the patient. Through the ethical pathway paved on information, interpretation, and deliberation, $\mathrm{PE}$ seems to eschew manipulation.

However, this may not be always the case in the daily practice of $\mathrm{PE}$, as confirmed by the fact that questionnaires ${ }^{20}$ are used which inquire, for example, whether patients are:

[...] asked for [their] ideas when [the patient and physician] made a treatment plan (almost never, generally not, sometimes, most of the time, and almost always).

Therefore, the agreement between the patient and educator may be a relative, generic concept that does not particularly encompass all of the aspects of the treatment plan, leaving the possibility that some of them may remain hidden. For example, a patient may agree on the implementation of a basal-bolus insulin regimen without having been clearly informed from the beginning that its full efficacy and safety may require intensive self-monitoring of blood glucose. One may also consider the prescription of glucagon-like peptide (GLP)-1 receptor agonists as a first step of introducing the patient to the use of injectable drugs utilized to facilitate his or her future acceptance of insulin. If these were done intentionally and covertly, proposing the basal-bolus regimen or GLP-1 receptor agonists would represent nothing but typical cases of the use of the foot-in-the-door technique, ie, of manipulation. Rubinelli indicated that manipulation is always intentional and relies on deception, which renders it definitively unethical. In contrast, proposing explicitly a GLP-1 receptor agonist to try before insulin, because it would represent the first experience of an injectable medication, would be ethical from this point of view.

Collectively, these considerations indicate the importance of precisely delineating the content of educational programs and checking with the patient whether he or she appreciates the specific consequences of the decisions on which there is agreement. In France, the law requests that patients provide informed consent to participate in official PE programs authorized by health agencies. ${ }^{28}$ This procedure may have the advantage of clearly disclosing that the patients will participate in a process basically aimed at changing their behavior. However, the informed consent procedure may represent an illusion as it usually comprises a general agreement signed a priori that does not specify the content of the

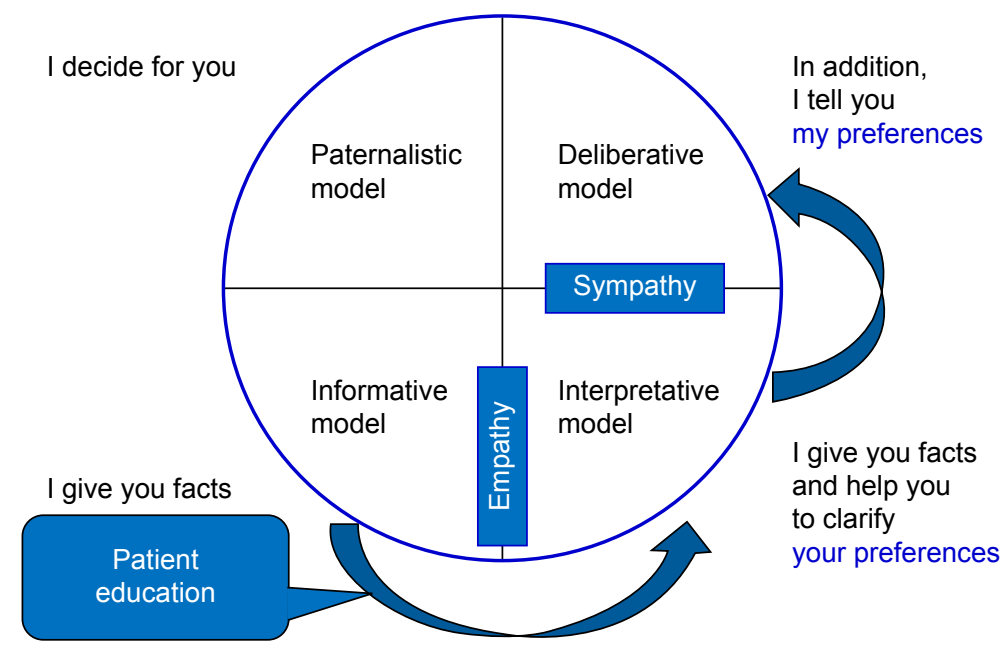

Figure 2 Patient education as an ethical pathway.

Notes: How patient education paves the way between the three models (informative, interpretative, and deliberative) of the physician-patient relationship ${ }^{26}$ and eschews the paternalistic model. The HCP uses empathy in his or her attempt to clarify the patient's preferences. He or she uses sympathy when telling the patient about his or her own preferences. Reproduced from Reach G. Patient autonomy in chronic care: solving a paradox. Patient Prefer Adherence. 20I4;8:15-24. ${ }^{27}$ 
agreement in advance. It would be fair to ask patients to provide their consent to a prespecified educational program rather than on the general principle of participating in a PE program, where an apparent desire for transparency actually leads to the proposal of something that is nothing but an opaque procedure that may not even be understood by those patients who would benefit the most from PE.

\section{The reflectivity requirement}

In the first part of this article, we observed that nudge techniques use psychology to influence human decisions ${ }^{3}$ and that Hansen and Jespersen identified two types of nudges: ${ }^{5}$ those that act only at the automatic level of thinking to change people's behaviors (type 1 nudges) and those that change behaviors through influencing cognitive choices (type 2 nudges). Regarding PE, one may guess that it works at the cognitive and reflective system 2. PE is largely based on a discussion of information provided to the patient, which is illustrated by the advice part of the $5 \mathrm{As}$ mode ${ }^{20}$ and by the informative, interpretative, and deliberative steps of the PE-as-an-ethical pathway model (Figure 2) ${ }^{27}$ This pathway suggested that $\mathrm{PE}$ is based on the cognitive-based definition of person autonomy proposed by Frankfurt ${ }^{29}$ and Dworkin, ${ }^{30}$ according to which an autonomous person is a being endowed with reflectivity, ie, having second-order mental states (eg, a belief about a belief or a desire about a desire), making it possible to critically evaluate one's mental states and eventually - on the basis of this reflection - to change his or her mind. In this framework, the very presence of deliberation in the last step of the pathway would warrant the presence of reflectivity in PE, and thereby its ethical justification. ${ }^{27}$

However, here again, there are obviously several breaches in the assumption that $\mathrm{PE}$ always works at the cognitive level. First, patients' cognitions can be biased: due to the uncertainty associated with the result of any action, they do not base their decisions only on pure rational arguments, and we have previously suggested that patient nonadherence may be in some way a manifestation of human irrationality. ${ }^{31}$ The content of the patients' beliefs may be false, influencing their choices in the direction of a suboptimal decision; ${ }^{32}$ they may have an aversion for losses that is greater than their attraction for gains; ${ }^{33}$ they may prefer a smaller but more immediate reward (eg, tasty but unhealthy foods) to greater long-term benefits (eg, the preservation of health), ${ }^{34}$ they may sometimes have a short temporal horizon; ${ }^{35}$ their cognition may use powerful mental mechanisms or heuristics ${ }^{36}$ that make it possible to reason rapidly but may represent a source of cognitive biases; ${ }^{4}$ and finally, they may be under the influence of emotions. ${ }^{37}$ If patients' cognitions are biased as a consequence of some of these effects, the role of PE may be to help patients recognize the existence of a bias and get rid of them. ${ }^{10,38}$ Consider, for example, a patient who is strongly refusing insulin because he or she falsely believes that insulin therapy is incompatible with the practices of Ramadan in which he or she eagerly wants to engage. An explanation of the basal-bolus insulin regimen indicating that it is compatible with religious fasting may help him or her to change his or her mind. In the same manner, as emotions are involved in decision processes (Figure 1), a physician may use emotions to persuade a patient to adopt a healthy behavior. Swindell et al considered the example of a doctor encouraging the patients to anticipate the regret they may feel (toward themselves and their children) if they continue to smoke and then develop lung cancer. ${ }^{10}$

There is another limitation to the reflective requirement ethically justifying PE. In the advice part of the $5 \mathrm{As}$ model, PE provides information on pathology and therapy as well as their respective risks. However, the way this information is provided and received may be biased. It often happens that people have difficulties in understanding the concept of the benefit/ risk ratio, and they are very sensitive to the frame heuristics. For example, in a fictive setup of decisions regarding cancer therapy, the attractiveness of surgery related to radiation was substantially greater when the problem was framed in terms of the probability of living rather than dying. ${ }^{39}$ In the same vein, people are generally more sensitive to relative than absolute risks; thus, for example, doctors who want to persuade a patient to accept a mammography when indicated may take advantage of this bias. ${ }^{10}$ Moreover, the way the information is provided is not and cannot be neutral. For example, the number of arguments that people use to make a decision is limited, a concept known as Ockham's razor. A physician, being aware of this psychological flaw, may therefore first provide the choice that he or she thinks will be the best for the patient. However, there will always be a choice that is provided first. Thus, physicians may influence their patients' choices without wanting or even recognizing it. ${ }^{9}$

\section{Shaping the patients' desires and the unavoidability of persuasion in the practice of PE}

In general, when care providers implement PE to influence patients to change their behaviors, they do it for the patients' good in the same vein as nudges decided by public authorities are for the good of the target population. We also mentioned that in some cases, even manipulation can be used for the welfare of the people. Hansen and Jespersen ${ }^{5}$ have provided examples of nontransparent type 1 nudges that may be 
evaluated as truly paternalistic interventions and that still may be beneficial; consider again, for example, the change in the plate sizes leading to a decrease in the caloric intake of employees eating in a cafeteria.

This article aimed to suggest that these concepts may be relevant to examining the ethics of $\mathrm{PE}$. The generalization of nudge elicited an important ethical debate ${ }^{5-7,16}$ aimed at clarifying the red line between acceptable and unacceptable forms of nudge, showing the importance of transparency and preserving the possibility for nudgees to resist what may represent an impediment to their autonomy. In the same vein, it is therefore warranted to critically examine the ethics of PE. It is important to point out that while nudge represents a method used by health or political authorities for improving the welfare of populations, $\mathrm{PE}$ is a process involving the relationship between health care providers and individual patients. Therefore, PE is ethically more exacting than nudge, maybe because in an interpersonal relationship, the care provider has the direct responsibility of preserving the autonomy of a person whom he or she knows, while the owner of the cafeteria or the manager of the airport toilets will never personally know the people subjected to their nudges.

PE not only provides knowledge but also aims at changing people's behaviors; ${ }^{17}$ in other words, shaping the patient's desires and beliefs that are the direct drivers of their actions (Figure 1). It happens that the patients' behaviors are in conflict with their own best interests; nonadherence to a good treatment may be a consequence of numerous psychological flaws leading to what we have referred to as medical irrationality. ${ }^{31}$ Thus, the first role of PE may be to help patients remove the biases that push them in a direction that is not in agreement with what they think to be in their best interests; therefore, PE uses persuasion here. Shaw and Elger ${ }^{38}$ noted that:

Removing biased interpretation of information is persuasion because the physician is attempting to change the patient's belief to help the patient make a more rational choice.

The aim of persuasion at removing biases was also noted by Dubov:" "persuasion is not deception but rather the art of making the truth apparent."

However, by aiming at changing the patients' desires and beliefs, a primary issue emerging from this discussion was the possible intrusive effect of PE that may jeopardize the patient's autonomy. This is why among the 5As of the model describing the practice of $\mathrm{PE}$, agreement between the patient and the educator was found to be of paramount importance not only to warrant the outcome of the PE process (the patient will adhere to the personal action plan that is decided) but also to justify it from an ethical point of view. However, we also observed that the value of this agreement may itself be jeopardized by the non-neutral attitude of the educator, who may be pushed to use it for the best interest of the patients through varied techniques of communication taking advantage of the psychological flaws that limit the patients' rationality, exactly in the same manner that, for beneficial purposes, nudge aims at orienting peoples' behaviors and choices by more or less transparent and reflectivity-based techniques.

We also observed that a convinced educator may wish to persuade the patient. The use of persuasion may actually be unavoidable, and even ethically justified, but must be controlled. Swindell et a ${ }^{40}$ proposed that:

Even if clinicians could extricate their values and avoid influencing their patients, it is by no means clear that doing so would serve their patients' interests.

They remind us that:

Professional ethics dictate that physicians explicitly counter temptations to take advantage of framing and other decisional approaches to promote goals other than the promotion of their patients' (or, debatably, society's) best interests.

They also pointed out ${ }^{10}$ that:

A patient's best interest and goals are determined by the patient and not by the physician. The physician is merely ascertaining them and rebiasing the patient toward them.

This last warning gives its full value to the assessment part of the 5As model of PE and to the interpretative step of the PEas-an-ethical pathway model (Figure 2). Finally, Dubov also demonstrated that persuasion is acceptable only if the health care provider never exploits the patient's weaknesses. ${ }^{9}$

\section{Conclusion: trust as the core of the person-centered model of care}

We arrive to the main conclusion of this article: shaping an agreement between two partners is possible only in the context of trust, in which the interests of the patient and the healthcare system come together under the concept of “encapsulated interest” developed by Russell Hardin: ${ }^{41}$

I trust you because I think it is in your best interest to take my interests in the relevant matter seriously in the following sense [...] You therefore have your own interest in taking my interests into account.

The importance of mutual trust was recognized in a similar way by Shinebourne and Bush: ${ }^{42}$ if a certain dose of 
paternalism is found in the deliberative model, its imposition may be:

A reflection of what many patients wish for. That is, to have medical care based on mutual trust between doctor and patient with the assumption that as a member of a profession, the doctor will make choices in the best interests of the patient.

Other patients may prefer the principle of shared decisionmaking ${ }^{43}$ based on an exchange about respective preferences and care. Here also, trust is necessary because preferences are values; ${ }^{25}$ only in a climate of trust one can exchange regarding values. This ability of the doctor to exchange, ie, to the practice of $\mathrm{PE}$, is a condition of trust, ${ }^{44}$ which may be important if one realizes that trust is one of the determinants of the patient's acceptance of treatment intensification. ${ }^{45}$ A study also showed that the physicians' comprehensive (whole person) knowledge of the patients and those patients' trust in their physicians were the variables most strongly associated with adherence. ${ }^{46}$ Incidentally, this suggests that doctors cannot completely delegate PE to a diabetes educator or to a nurse. This would be detrimental in terms of patients' adherence. Indeed, the doctors, and not the diabetes educators or the nurses, prescribe the treatment to which patients may or may not adhere according to the trust that they have in their doctor. PE is an integral part of care, which means that care cannot be split into two parts: prescription and PE. PE and care are the same thing; they belong to each other.
Therefore, we propose a model for the patient-physician relationship (Figure 3) linking the 5As model of PE to trust in a dynamic manner. PE, by collecting information (from Assessment) and providing information (Advise) to the patient, actually generates trust. A trusting patient-health care provider relationship will make it possible to obtain an Agreement, which is nothing but the basis of a shared medical decision that in turn reinforces trust. Based on this agreement, the educator will Assist the patient implementing the personal action plan, and they will Arrange together the follow-up necessary for the implementation of PE as an integral part of care.

This model shows how PE can lead to better care, with trust playing a central role. Trust is generated by $\mathrm{PE}$ and in turn makes agreement, a part of PE, possible. As indicated by Sagoff:

Trust is the sine qua non of medicine [...]. Where there is trust, paternalism is unnecessary, where there is no trust, it is unconscionable. ${ }^{47}$

Trust excludes deception, and this may actually represent its operational definition in the same sense that manipulation is defined by the presence of covert deception. For O'Neill, ${ }^{48}$ the obligation for physicians to avoid deception will be expressed:

In refraining from lying, from false promising, from promise breaking, from misrepresentation, from manipulation [...]. More positively, it will be expressed through truthful

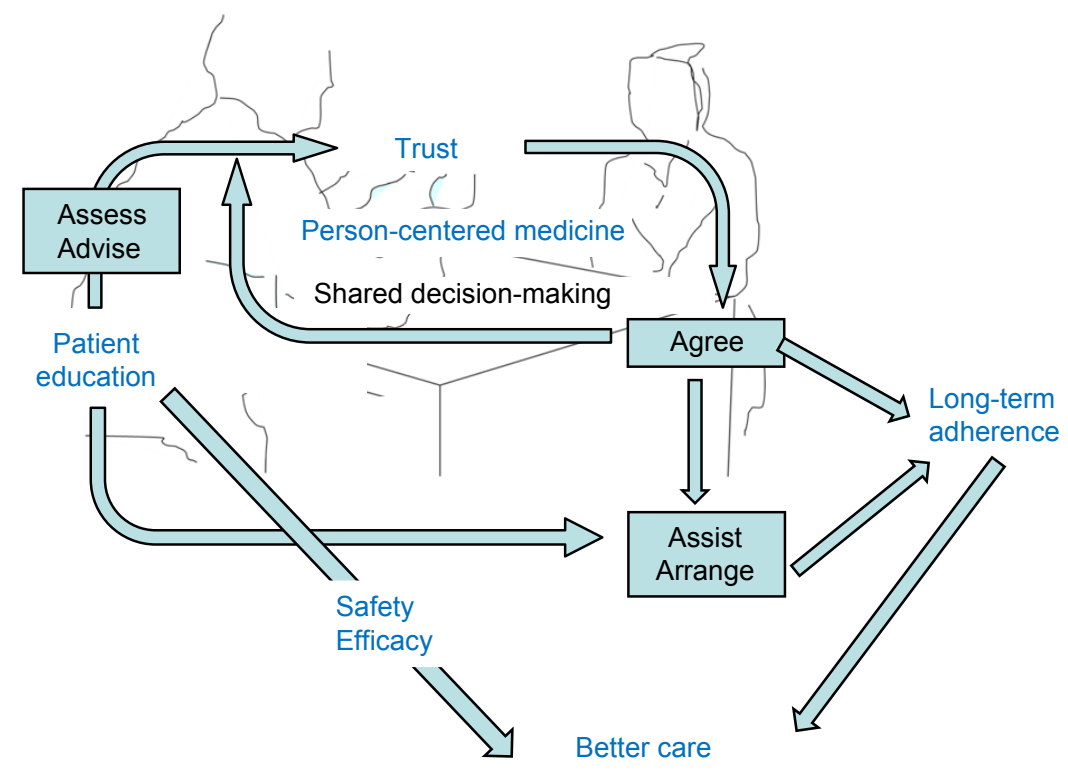

Figure 3 The dynamic interplay between the 5 As of patient education and trust: the bases of person-centered medicine.

Notes: A trust-based model of the patient-physician relationship: how patient education generates trust and indirectly improves the patients' long-term adherence. Patient education leads to better care by providing technical information (safety and efficacy) and by improving patient long-term adherence. In this model, both the doctor and the patient act as persons. Patient education paves therefore the way to person-centered medicine, and trust is an essential constituent of this model. 
communication, through care not to mislead, through avoidance of exaggeration, through simplicity and explicitness, through honesty in dealing with others.

However, a trust-based relationship does not exclude persuasion. Therefore, we conclude that, from a Kantian perspective, PE can use different kinds of guidance, including persuasion and nudge-like forms of influence (nudge is a form of influence ${ }^{49}$ ) as a part of the interpersonal patient-doctor interaction at the condition of being exclusively guided by the patient's best interests and avoiding any form of intentional deception.

In the model shown in Figure 3, both the health care provider and the patient act as persons. PE paves therefore the way to a person-centered model of care. In a companion article,$^{50}$ we showed why such a model may represent a solution to patients' nonadherence by taking into account the complexity of patients' and doctors' thought. The discussion presented herein shows how to implement this model in an ethical manner, escaping the danger of manipulating patients, which, as shown in this article, is real. This discussion on the ethics of PE demonstrates the need to consider trust as the core of the person-centered care model: trust enables the encounter of the two complex thoughts of patient and doctor.

\section{Acknowledgment}

The author wishes to express his gratitude to Sadek Béloucif and Yashar Saghai for fruitful discussions of this manuscript.

\section{Disclosure}

The author reports no conflicts of interest in this work.

\section{References}

1. WHO Report. Adherence to Long-Term Therapies, Evidence for Action. Geneva: WHO; 2003:211.

2. WHO-Europe. World Health Organization, Regional Office for Europe, Therapeutic Patient Education - Continuing Education Programmes for Health Care Providers in the Field of Prevention of Chronic Diseases. Report of a WHO Working Group; 1998; Copenhagen.

3. Thaler RH, Sunstein CR. Nudge: Improving Decisions about Health, Wealth, and Happiness. New Haven: Yale University Press; 2008.

4. Kahneman D. Thinking, Fast and Slow. London: Allen Lane; 2011.

5. Hansen PG, Jespersen AM. Nudge and the manipulation of choice. A framework for the responsible use of nudge approach to behavior change in public policy. Eur J Risk Regul. 2013;1:3-28.

6. Cohen S. Nudging and informed consent. Am J Bioethics. 2013;13: 3-11.

7. Saghai Y. Salvaging the concept of nudge. J Med Ethics. 2013;39(8): 487-493.

8. Rubinelli S. Rational versus unreasonable persuasion in doctor-patient communication: a normative account. Patient Educ Couns. 2013;92: 296-301.

9. Dubov A. Ethical persuasion: the rhetoric of communication in critical care. J Eval Clin Pract. 2015;21:496-502.
10. Swindell JS, McGuire AL, Halpern SD. Beneficent persuasion: techniques and ethical guidelines to improve patients' decisions. Ann Fam Med. 2010;8:260-264.

11. Beauchamp T, Childress J. Principles of Biomedical Ethics. 1st ed. Oxford, NY; Toronto: Oxford University Press; 1979.

12. Joule RV, Beauvois JL. Petit Traité de manipulation à l'usage des honnêtes gens. Grenoble: Presses Universitaires de Grenoble; 1987. [Première Edition].

13. Burger JM. The foot-in-the door procedure: a multiple-process analysis and review. Pers Soc Psychol Rev. 1999;3:303-325.

14. Kiesler CA. The Psychology of Commitment. New York, NY: Academic; 1971.

15. Joule RV, Beauvois JL. La Soumission librement consentie: Comment amener les gens à faire librement ce qu'ils doivent faire. Paris: PUF; 1998.

16. Bovens L. The ethics of nudge. In: Grüne-Yanoff T, Hansson SO, editors. Preference Change: Approaches from Philosophy, Economics and Psychology. Theory and Decision Library A. Berlin: Springer; 2008: 207-219.

17. Peyrot M. Behavior change in patient education. Diabetes Educ. 1999; 25(suppl 6):62-73.

18. Bloom PN, McBride CM, Pollak KI, Schwartz-Bloom RD, Lipkus IM. Recruiting teen smokers in shopping malls to a smoking-cessation program using the foot-in-the-door technique. J Appl Soc Psychol. 2006;36:1129-1144.

19. Siminerio L. Models for diabetes education. In: Weinger K, Carver CA, editors. Contemporary Diabetes: Educating Your Patients with Diabetes. Berlin: Springer; 2009:29-43.

20. Glasgow RE, Emont S, Miller DC. Assessing delivery of the five 'As' for patient-centered counseling. Health Promot Int. 2006;21:245-255.

21. Davidson D. Actions, reasons, and causes. J Phil. 1963;60:685-700.

22. Reach G. An intentionalist model of patient adherence. In: The Mental Mechanisms of Patient Adherence to Long-Term Therapies, Mind and Care, Foreword by Pascal Engel, Philosophy and Medicine Series. Berlin: Springer; 2015.

23. Searle J. Intentionality: An Essay in the Philosophy of Mind. Cambridge: Cambridge University Press; 1983.

24. Davidson D. First person authority. Dialectica. 1984;38(2-3):101-112.

25. Lewis D. Dispositional theories of values. Proc Aristotelian Soc. 1989; 63:113-137.

26. Emanuel EJ, Emanuel LL. Four models of the physician-patient relationship. JAMA. 1992;267:2221-2226.

27. Reach G. Patient autonomy in chronic care: solving a paradox. Patient Prefer Adherence. 2014;8:15-24.

28. Agence Régionale de Santé. Éducation Thérapeutique du Patient: Apprendre à mieux vivre avec une maladie chronique. Available from: http://www.ars.iledefrance.sante.fr/fileadmin/ILE-DE-FRANCE/ARS/ Presse/8_Communiques_presse_2011_2012/DP_ETP_Vdef_27.06.12. pdf. Accessed October 31, 2015.

29. Frankfurt H. Freedom of the will and the concept of has a person. J Phil. 1971;68:5-20.

30. Dworkin G. The Theory and Practice of Autonomy. Cambridge: Cambridge University Press; 1988.

31. Reach G. Patients' nonadherence and doctors' clinical inertia: two faces of medical irrationality. Diabetes Manage. 2015;5:167-181.

32. Ullrich PF Jr, Vaccaro AR. Patient education on the internet: opportunities and pitfalls. Spine. 2002;27:E185-E188.

33. Kahneman D, Tversky A. Prospect theory: an analysis of decision under risk. Econometrica. 1979;47:263-292.

34. Story GW, Vlaev I, Seymour B, Darzi A, Dolan RJ. Does temporal discounting explain unhealthy behavior? A systematic review and reinforcement learning perspective. Front Behav Neurosci. 2014; 8:76-86.

35. Jones BA, Landes RD, Yi R, Bickel WK. Temporal horizon: modulation by smoking status and gender. Drug Alcohol Depend. 2009;104(suppl 1): S87-S93.

36. Tversky A, Kahneman D. Judgment under uncertainty: heuristics and biases. Science. 1974;185:1124-1131. 
37. Baumeister RF, Vohs KD, DeWall CN, Zhang L. How emotion shapes behavior: feedback, anticipation and reflection, rather than direct causation. Pers Soc Psychol Rev. 2007;11:167-203.

38. Shaw D, Elger B. Evidence-based persuasion: an ethical imperative. JAMA. 2013;24:1689-1690.

39. McNeil BJ, Pauker SG, Sox HC Jr, Tversky A. On the elicitation of preferences for alternative therapies. N Engl J Med. 1982;306:1259-1262.

40. Swindell JS, McGuire AL, Halpern SD. Shaping patients' decisions. Chest. 2011;139:424-429.

41. Hardin R. Trust and Trustworthiness. New York, NY: Russell Sage Foundation; 2004.

42. Shinebourne EA, Bush A. For paternalism in the doctor-patient relationship. In: Gillon R, Lloyd A, editors. Principles of Health Care Ethics. Chichester: Wiley; 1994:399-408.

43. Kon AA. The shared decision-making continuum. JAMA. 2010;304: 903-904.
44. Thom DH; Stanford Trust Study Physicians. Physician behaviors that predict patient trust. Fam Pract. 2001;50:323-328.

45. Zikmund-Fisher BJ, Hofer TP, Klamerus ML, Kerr EA. First things first: difficulty with current medications is associated with patient willingness to add new ones. Patient. 2009;2:221-231.

46. Safran DG, Taira DA, Rogers WH, Kosinski M, Ware JE, Tarlov AR. Linking primary care performance to outcomes of care. J Fam Pract. 1998;47:213-220.

47. Sagoff M. Trust versus paternalism. Am J Bioethics. 2013;13:20-21.

48. O'Neill O. Autonomy and Trust in Bioethics. Cambridge: Cambridge University Press; 2002:98.

49. Saghai Y. Nudging in interpersonal contexts. Am J Bioethics. 2013; $13: 33-34$.

50. Reach G. Simplistic and complex thought in medicine: the rationale for a person-centered model as a medical revolution. Patient Prefer Adher. 2016;10:449-457.

\section{Publish your work in this journal}

Patient Preference and Adherence is an international, peer-reviewed, open access journal that focuses on the growing importance of patient preference and adherence throughout the therapeutic continuum. Patient satisfaction, acceptability, quality of life, compliance, persistence and their role in developing new therapeutic modalities and compounds to optimize clinical outcomes for existing disease states are major areas of interest for the journal. This journal has been accepted for indexing on PubMed Central. The manuscript management system is completely online and includes a very quick and fair peer-review system, which is all easy to use. Visit http://www. dovepress.com/testimonials.php to read real quotes from published authors. 